\title{
Comparison of Compliance of Different Iron Chelators Including Original and Bioequivalents of Deferasirox
}

\author{
Tekin Aksu *,1, [MD] \\ ORCID ID: 0000-0003-4968-109X \\ Namık Yaşar Özbek ${ }^{2}$, [MD] \\ ORCID ID: 0000-0001-6857-0681 \\ Murat Söker ${ }^{3}$, [MD] \\ ORCID ID: 0000-0001-8463-2723 \\ Çağrı Coşkun ${ }^{1}$, [MD] \\ ORCID ID: 0000-0001-9725-8355 \\ Zeliha Güzelküçük², [MD] \\ ORCID ID: 0000-0003-1462-6867 \\ Hülya Veysiye $\mathrm{Uze}^{3}$, [MD] \\ ORCID ID: 0000-0002-3037-2353 \\ Neşe Yaralı², [MD] \\ ORCID ID: 0000-0001-5488-2385 \\ Fatma Gümrük'1, [MD] \\ ORCID ID: 0000-0001-5102-0624 \\ Şule Ünal', [MD] \\ ORCID ID: 0000-0002-3083-8547 \\ ${ }^{1}$ Hacettepe University Faculty of Medicine, Department \\ of Pediatrics, Division of Hematology, Ankara, Turkey \\ ${ }^{2}$ Ankara City Hospital, Department of Pediatric \\ Hematology, Ankara, Turkey \\ ${ }^{3}$ Dicle University Faculty of Medicine, Department \\ of Pediatrics, Division of Hematology and Oncology, \\ Diyarbakır, Turkey
}

*Corresponding author: Tekin Aksu

Hacettepe University Faculty of Medicine, Department of Pediatrics, Division of Hematology, Ankara, Turkey Ihsan Doğramacı Childrens Hospital, Floor B, 06100, Sıhhiye, Ankara, Turkey

Phone / Fax number: 00903123051172 /00903123114990 tekinaksu@gmail.com

Received: 26 August 2020, Accepted: 21 September 2020

Published online: 30 September 2020

\section{we) ABSTRACT Cem}

Objective: The current iron chelation therapy regimens include deferoxamine, deferiprone, and deferasirox in transfusion-dependent patients. Compliance with iron-chelating therapy is one of the significant determinants of mortality and morbidities related to iron overload in chronically transfused patients. This survey aims to compare the compliance to treatment with deferoxamine, deferiprone, and deferasirox and the taste of oral formulations in three hematology centers from Turkey. Moreover, the bioequivalent (generic) formulations of dispersible deferasirox tablets were compared with the original formulation in terms of taste and treatment compliance.

Material and Methods: A written questionnaire with a list of pre-set questions was applied to measure patient-reported outcomes to a total of 85 patients, where 77 had beta-thalassemia major, 7 had beta-thalassemia intermedia, and 1 had sickle cell anemia diagnoses.

Results: The patients' median age at enrollment was 15 years (range $7-42$ ). The compliance was below $50 \%$ in 8 (18.6\%), $4(16 \%)$, and $5(6.7 \%)$ in patients receiving deferoxamine, deferiprone, and deferasirox, respectively. Additionally the compliance was below $80 \%$ in $16(37.2 \%), 9(36 \%)$, and $17(22.6 \%)$ in patients receiving deferoxamine, deferiprone, and deferasirox, respectively. It was found that 39 (47\%) patients had compliance problems due to the dispersible deferasirox tablet formulations' taste, except combination therapies. There was no difference between the currently used oral chelators in terms of taste and treatment compliance.

Conclusion: This study draws attention to compliance problems in patients with iron-loading anemias, partly due to the unpleasant taste of deferasirox. Improving patient satisfaction and compliance with iron-chelator therapy may reduce complications of iron overload.

Keywords: Beta-thalassemia major, beta-thalassemia intermedia, iron-chelating therapy, compliance

\section{INTRODUCTION}

Iron overload is inevitable when iron intake is increased because there is no excretion mechanism for iron in the body. Red blood cell transfusions are the primary cause of iron overload in transfusion-dependent thalassemias, and increased gastrointestinal iron absorption has an additional effect
[1]. Iron accumulation is toxic to the body, particularly to the heart, liver, and endocrine organs. It is the most important cause of morbidity and mortality in patients with transfusion-dependent hematological diseases like thalassemia major (TM), and DiamondBlackfan anemia [2]. Iron chelation therapy impedes 
iron accumulation by increasing excretion via urine and or feces, and even it diminishes excess tissue iron. As these patients are transfusion-dependent, chelation therapy should be administered for a lifetime. Safety, tolerability, and convenience of these drugs are essential for compliance, the wellbeing and the support of the patients are other accompanying factors [3]. The choice of the chelator or combination therapies are the most significant factors in preventing disease-related complications [2]. Also, chelators should be tailored to patients regarding clinical needs and compliance. The current iron-chelating agents are deferoxamine mesylate (DFO, Desferal ${ }^{\oplus}$, Novartis, Switzerland), deferiprone (DFP, Ferriprox ${ }^{\circledast}$, Apotex, Canada), and dispersable deferasirox (DFX, Exjade ${ }^{\oplus}$, Novartis) tablets in transfusion-dependent patients, which have been widely used since 1984, 2004, and 2007 respectively in Turkey [1]. Deferoxamine is given parenterally, yet DFP and DFX are given orally. Oral DFX obtained a better improvement over parenteral DFO concerning compliance and satisfaction [4].

Also, there are variable DFX generics in Turkey in recent years. We evaluated the compliance of the DFO, DFP, and DFX in patients with beta-thalassemia major ( $\beta T M)$, beta-thalassemia intermedia $(\beta T I)$, and sickle cell anemia (SCA). Furthermore, bioequivalent (generic) formulations of dispersible DFX tablets were compared with the original formulation in terms of taste and treatment compliance.

\section{MATERIAL and METHODS}

Hacettepe University Institutional Review Board approval (No:2020-11-10) and written consent of the patients and their parents were obtained. In this cross-sectional study, 85 patients were enrolled from three different hematology centers in Turkey. We included patients with beta-thalassemia major, beta-thalassemia intermedia, and sickle cell anemia diagnosis who are aged more than seven-years-old. Most of the patients were transfusion-dependent and using various iron chelators. A written questionnaire with a list of pre-set questions was applied to patients or families to measure patient-reported outcomes. Patients' age, gender, diagnosis, personal iron chelator history, current iron chelator therapy, and the dose of the drugs were obtained. The original iron chelator drugs (DFO, DFP, DFX), and generics of DFX were addressed in the questionnaire. We evaluated compliance with different iron-chelating drugs and the compliance and the taste of oral chelators, in particular, different dispersible DFX original and generic formulations. All questions regarding compliance are scored on a scale 0 to 100 percent, with 100 representing the highest level of compliance possible. As an example, 'If you used deferasirox, what percentage would you rate your compliance?' question used to measure compliance of DFX. And the questions regarding taste are closed-ended questions, which can be answered by a simple "yes" or "no". As an example, 'Are there any chelators that you don't want to use because of their taste?' question used to measure satisfaction with the taste. Face to face interview method was used for data collection.

\section{Statistical Analysis}

Statistical analysis was performed by using The jamovi project (2019). jamovi. (Version 1.1) [Computer Software, Retrieved from https://www. jamovi.org]. Descriptive analyses were presented using means for normally distributed and median for non-normally distributed variables. The MannWhitney U test, Chi-Square test, and Kruskal Wallis test were used to determine if there are statistically significant differences between variables. $p$-value $<0,05$ is statistically significant.

\section{RESULTS}

A total of 85 patients were included in the study, where 77 patients with beta-thalassemia major, 7 with beta-thalassemia intermedia, and 1 with sickle cell anemia diagnoses. The patients' median age at enrollment was 15 years (range $7-42$ ), and 47 (55\%) of them were girls. Personal history revealed, 20 patients $(23.5 \%)$ received one kind of iron chelator, 27 (31.8\%) 2 types, 30 (35.3\%) 3 types, 5 patients (5.9\%) 4 types, and 3 patients (3.5\%) received 5 different iron chelators to date (Table 1). Forty-three patients had a history of DFO therapy, 25 of them were female, and 18 were male (Table 2). Eight patients $(18.6 \%)$ noted that compliance with DFO was less than $50 \%$, and 16 patients $(37,2 \%)$ noted compliance below $80 \%$. There was no difference in drug 
compliance between male and female patients ( $p$ $>0.05$ ). Twenty-five patients had a history of use of DFP therapy, 10 of them were female, and 15 were male (Table 2). Four patients (16\%) noted that the compliance to DFP was less than $50 \%$, and 9 (36\%) reported drug compliance below $80 \%$. There was no difference between girls and boys in terms of deferiprone compliance $(p=0.69)$. Seventy-five

Table 1. Baseline characteristics of the patients. patients had a history of DFX therapy, 41 of them were female, and 34 were male (Table 2). Five patients $(6.7 \%)$ noted that the compliance to DFX was less than 50\%, 17 (22.6\%) stated that drug compliance was less than $80 \%$. There was no difference between girls and boys in terms of deferasirox compliance $(p=0.27)$

\begin{tabular}{|c|c|}
\hline Patients & $\begin{array}{l}\text { All patients } \\
\mathrm{n}=85(\%)\end{array}$ \\
\hline $\begin{array}{l}\text { Median age at enrollment (years) } \\
\text { Range }\end{array}$ & $\begin{array}{c}15 \\
7-42\end{array}$ \\
\hline $\begin{array}{l}\text { Gender } \\
\text { Female } \\
\text { Male }\end{array}$ & $\begin{array}{l}47(55 \%) \\
38(45 \%)\end{array}$ \\
\hline $\begin{array}{l}\text { Diagnosis } \\
\beta T M \\
\beta T I \\
\text { SCA }\end{array}$ & $\begin{array}{c}77(91 \%) \\
7(8 \%) \\
1(1 \%)\end{array}$ \\
\hline $\begin{array}{l}\text { Previous chelation } \\
\text { One kind } \\
\text { Two kind } \\
\text { Three kind } \\
\text { Four kind } \\
\text { Five kind }\end{array}$ & $\begin{array}{c}20(23.5 \%) \\
27(31.8 \%) \\
30(35.3 \%) \\
5(5.9 \%) \\
3(3.5 \%)\end{array}$ \\
\hline
\end{tabular}

BTM: Beta-thalassemia major, $\beta$ TI: Beta-thalassemia intermedia, SCA: Sickle cell anemia

Table 2. Comparison of compliance with deferoxamine, deferiprone, and deferasirox in patients.

\begin{tabular}{|l|c|c|c|c|}
\hline \multicolumn{1}{|l|}{} & $\begin{array}{c}\text { Deferoxamine } \\
\text { (DFO) }\end{array}$ & $\begin{array}{c}\text { Deferiprone } \\
\text { (DFP) }\end{array}$ & $\begin{array}{c}\text { Deferasirox } \\
\text { (DFX) }\end{array}$ & p value \\
Compliance $\mathrm{n}(\%)$ & 43 & 25 & 75 & 0.416 \\
$<50 \%$ & $8(18.6 \%)$ & $4(16 \%)$ & $5(6.7 \%)$ & 0.276 \\
$<80 \%$ & $9(36 \%)$ & $17(22.6 \%)$ & \\
\hline
\end{tabular}


Currently, a total of 49 patients receiving Exjade, while 19 Enferox, 9 Fuarte, 3 Febind, 3 Fesor, and 9 Ferriprox, except DFO (Table 3). Seven of the patients were receiving combination therapies, including Exjade-Ferriprox in four, Enferox-Ferriprox in two, and Febind-Ferriprox in one patient. It was found that $39(47 \%)$ patients had compliance problems due to the dispersible DFX tablet formulations' taste, except combination therapies. It was observed that 18 patients receiving Exjade (36.7\%), 9 patients Enferox (47.3\%), 7 patients Fuarte (77.7\%), Febind 2 (66.6\%), and Fesor 3 (100\%) did not receive their treatment regularly due to chelator taste. Also, three patient on Exjade + Ferriprox combination and one patient on Ferriprox treatment did not receive their treatment regularly due to chelator taste. There was no statistically significant difference between the deferoxamine, deferiprone, and deferasirox in terms of treatment compliance $(p=0.276)$. Besides, there was no statistically significant difference between dispersible deferasirox original and generic formulations concerning compliance problems due to the chelators' taste $(p=0.088)$.

Table 3. Comparison of compliance problems due to the chelators' taste with dispersible deferasirox original and generic formulations.

\begin{tabular}{|c|c|c|c|c|c|c|}
\hline & Exjade* & Enferox† & Fuarte $\neq \emptyset$ & Febind§ף & Fesor $\| \emptyset$ & $p$ value \\
\hline $\mathrm{n}=$ & 49 & 19 & 9 & 3 & 3 & \\
\hline Unpleasant taste $\mathrm{n}(\%)$ & $18(36.7)$ & $9(47.3)$ & $7(77.7)$ & $2(66.6)$ & $3(100)$ & 0.088 \\
\hline
\end{tabular}

* Novartis, Switzerland; †ILKO, Turkey; ¥Abdi İbrahim, Turkey; §Farma-Tek, Turkey; ||Sanovel, Turkey; $\uparrow$ Fuarte, Febind, and Fesor variables were combined in a single group and compared with Exjade and Enferox variables, due to limited case number.

\section{DISCUSSION}

This study focused on iron chelator preference, treatment compliance, and taste of DFX drugs in a group of patients mostly with thalassemia and illustrated a real-life experience. As with other diseases that require long-term treatment, including pediatric and adolescent patients, compliance could be challenging. The studies revealed that patients with iron-loading anemias have suboptimal compliance rates to iron-chelating therapy [5]. Estimated mean compliance to DFO ranged from 59 to 78 percent, while DFP was ranging from 79 to 98 percent [5]. A review of the literature suggests that compliance may be better with oral iron chelator therapy [5]. In this study, more than $1 / 3$ of surveyed patients noted modest compliance (below 80\%) to iron chelation therapies, particularly for DFO, DFP. Although it seems better than others in compliance with DFX treatment, $22.6 \%$ of the patients had inadequate compliance with DFX. Poor compliance with these two drugs might be related to time-consuming and parenteral administration of DFO, and three times a day oral administration of DFP. A study showed that the patients who were receiving DFX reported $90 \%$ compliance, whereas those receiving DFO reported $40 \%$ [6]. Additionally, a study reported similar and high compliance rates between DFP (95\%) and DFX $(97 \%)$ in pediatric patients with transfusion-dependent hemoglobinopathies [7]. This survey disclosed $77.4 \%$ of the patients reported more than $80 \%$ compliance with DFX, which is low in comparison to the published reports. The wide age range of patients and the inclusion of patients from regions with different socioeconomic status may have led to this result.

Additionally, half of the patients expressed the chelator taste caused their compliance problem. Particularly DFX and the generics have an unpleasant taste. However, there was no significant difference between the original drug and generics in terms of taste of the formulation and treatment 
compliance. Tsouana et al. reported that more than $50 \%$ of children had difficulties in taking DFX, commonly because of unpleasant taste [8]. However, more comprehensive studies, including more patients, are needed to delineate incompliance due to formulation taste. DFX tablets contain lactose and sodium lauryl sulfate (SLS) to improve solubility as non-active ingredients [9]. In generic drugs of DFX, these excipients are also in variable proportions. Half of the patients receiving DFX experienced gastrointestinal adverse events including, abdominal pain, diarrhea, nausea, and vomiting $[10,11]$. Some of the gastrointestinal side effects of DFX may be related to lactose and SLS content. However, a study disclosed that gastrointestinal signs and symptoms are not due to lactose intolerance in beta-thalassemia patients receiving DFX [12]. Therefore the etiology of these complaints is unknown and remains to be explored. Recently, a new film-coated tablet of DFX for oral administration was developed. Yet, it doesn't contain lactose and SLS in contrast to dispersable DFX tablets. Film-coated tablets recipients reported better compliance and greater satisfaction in comparison to dispersable DFX tablets. Moreover, film-coated tablet recipients noted no taste or aftertaste of the drug [3]. The limitations of this study majorly come from its cross-sectional nature, which is based on patient-oriented responses. Also, the patients' disease status, duration of previously used iron chelator therapy, and reason for switching between drugs were not addressed. The low number of patients using generic drugs may have affected the results. Another limitation of the study is that the side effects of drugs other than taste, which may affect compliance, were not investigated.

In conclusion, this study draws attention to compliance problems in patients with iron-loading anemias, partly due to the unpleasant taste of DFX. Improving patient satisfaction and compliance with iron-chelator therapy may reduce complications of iron overload.

\section{CONFLICT Of INTEREST STATEMENT}

The authors have no conflict of interest to declare. 


\section{we) REFERENCES CQm}

[1] Porter J, Viprakasit V. Iron overload and chelation. In Guidelines for the management of transfusion dependent thalassaemia (TDT), 3rd ed. Thalassaemia International Federation publication no: 20, 2014;42-75

[2] Porter JB. Optimizing iron chelation strategies in beta-thalassaemia major. Blood Rev. 2009;23:S3-7.

[3] Taher AT, Origa R, Perrotta S, et al. Patient-reported outcomes from a randomized phase II study of the deferasirox film-coated tablet in patients with transfusion-dependent anemias. Health Qual Life Outcomes. 2018;16:216.

[4] Cappellini MD, Bejaoui M, Agaoglu L, et al. Prospective evaluation of patient-reported outcomes during treatment with deferasirox or deferoxamine for iron overload in patients with beta-thalassemia. Clin Ther. 2007;29:909-917.

[5] Delea TE, Edelsberg J, Sofrygin O, et al. Consequences and costs of noncompliance with iron chelation therapy in patients with transfusion-dependent thalassemia: a literature review. Transfusion. 2007:47:1919-29.

[6] Haghpanah S, Zarei T, Zahedi Z, et al. Compliance and satisfaction with deferasirox (Exjade ${ }^{\oplus}$ ) compared with deferoxamine in patients with transfusion-dependent beta-thalassemia. Hematology. 2014;19:187-91.
[7] Maggio A, Kattamis A, Felisi M, et al. Evaluation of the efficacy and safety of deferiprone compared with deferasirox in paediatric patients with transfusion-dependent haemoglobinopathies (DEEP-2): a multicentre, randomised, open-label, non-inferiority, phase 3 trial. Lancet Haematol. 2020;7:e469-e478.

[8] Tsouana E, Kaya B, Gadong N, et al. Deferasirox for iron chelation in multitransfused children with sickle cell disease; longterm experience in the East London clinical haemoglobinopathy network. Eur J Haematol. 2015;94:336-42.

[9] Gülsün T, Akdağ Y, Izat N, et al. Effect of particle size and surfactant on the solubility, permeability and dissolution characteristics of deferasirox. J Res Pharm. 2019;23:851-859.

[10] Goldberg SL, Giardina PJ, Chirnomas D, et al. The palatability and tolerability of deferasirox taken with different beverages or foods. Pediatr Blood Cancer. 2013;60:1507-12.

[11] Stumpf JL. Deferasirox. Am J Health Syst Pharm. 2007;64:606-616

[12] Pazgal I, Brown M, Perets TT, et al. Lactose intolerance is not the cause of gastrointestinal adverse effects in beta thalassemia patients treated with deferasirox. Am J Hematol. 2014;89:938-9. 